\title{
ALSC CutTER
}

G. T. Schmitz

DEVELOPMENT DIVISION

JANUARY - MARCH 1976

Normal Process Development Endeavor No. 202

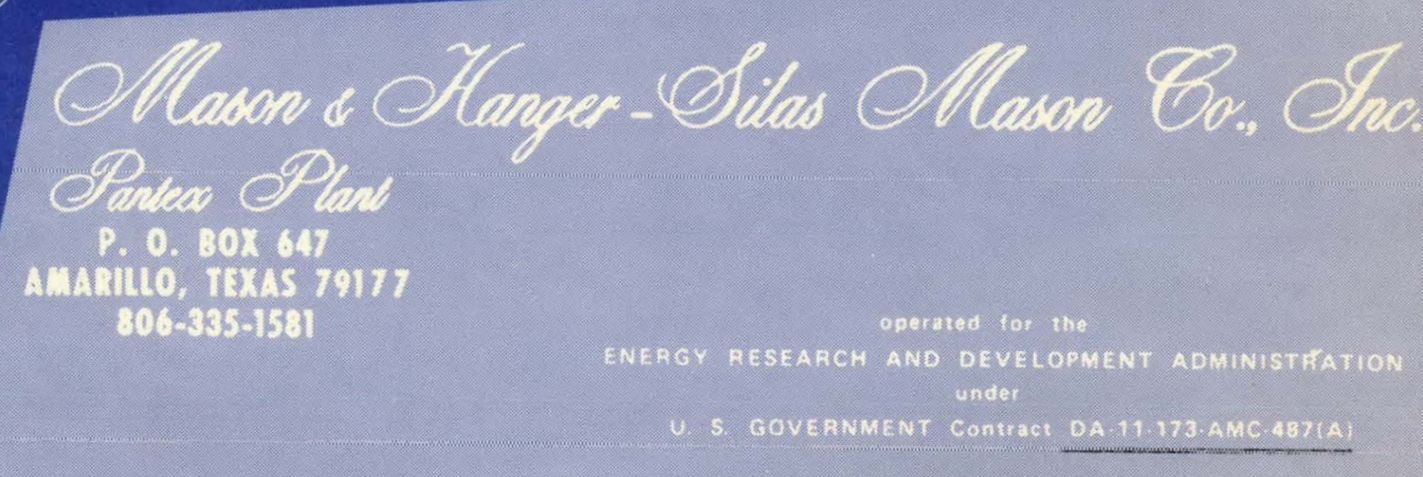




\section{DISCLAIMER}

This report was prepared as an account of work sponsored by an agency of the United States Government. Neither the United States Government nor any agency Thereof, nor any of their employees, makes any warranty, express or implied, or assumes any legal liability or responsibility for the accuracy, completeness, or usefulness of any information, apparatus, product, or process disclosed, or represents that its use would not infringe privately owned rights. Reference herein to any specific commercial product, process, or service by trade name, trademark, manufacturer, or otherwise does not necessarily constitute or imply its endorsement, recommendation, or favoring by the United States Government or any agency thereof. The views and opinions of authors expressed herein do not necessarily state or reflect those of the United States Government or any agency thereof. 


\section{DISCLAIMER}

Portions of this document may be illegible in electronic image products. Images are produced from the best available original document. 
This report was prepared as an account of work sponsored by the United States Government. Neither the United States nor the United States Energy Research and Development Administration, nor their employees, nor any of their contractors, subcontractors, or their employees, makes any warranty, express or implied, or assumes any legal liability or responsibility for the accuracy, completeness or usefulness of any information, apparatus, product or process disclosed, or represents that its use would not infringe privately-owned rights. 


\title{
ALSC CutTer
}

\author{
G. T. Schmitz \\ DEVELOPMENT DIVISION \\ January - March 1976 \\ Endeavor No. 202
}

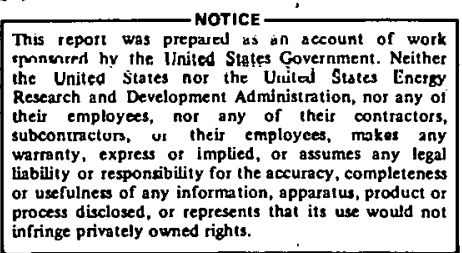




\section{ABSTRACT}

Aluminum sheath linear shaped charge (ALSC) containing HNS-II core explosive was specified as the explosive component in the MC 3125 design.

Technology and tooling for cutting and forming ALSC, HNS II, $5.3 \mathrm{~g} / \mathrm{m}$ core load, are described as preliminary developments to the manufacturing process.

\section{DISCUSSION}

\section{CUTTING}

Performance data for ALSC (HNS II) have been reported(1). Among these data, specifically, with reference to impact sensitivity, it was noted that HNS II-A demonstrated "a broad range of drop heights which produced an 'explosion'." Impact sensitivity (2 kg drop hammer) data generated at Pantex show $\mathrm{H}_{50}$ drop heights ranging from a low of $35 \mathrm{~cm}$ to $88 \mathrm{~cm}$ in the Type $12 \mathrm{~A}$ series reporting on 21 separate lots tested. Similarly the $\mathrm{H}_{50}$ drop heights for the Type 12B test series ranged from a low of about $50 \mathrm{~cm}$ to a high of $185 \mathrm{~cm}$. Furthermore, friction test results show deflagration type reactions at relatively low (4448 $\mathrm{N}$ ) normal forces with HNS I. Low density HNS II test specimens did not react; however, HNS II may, be sensitive to some type of frictional force.

Several techniques are known for cutting ALSC. These are:

1. Cleavage of the aluminum sheath and explosive core with a mechanical shear (Fig. 1).

2. Manually cutting through the aluminum sheath and explosive core with a jeweler's saw.

3. Manually scoring the aluminum sheath with a sharp instrument and breaking.

None of the above were considered to be acceptable as a safe and efficient manufacturing procedure. However, since the MC 3125 design specified the initiation mode to be through the aluminum sheath rather than in line or end lighting and a lap rather than butt joint to make the $360^{\circ}$ ALSC configuration, a mechanized version of the "score and break" technique is believed to be a safe and efficient method. A mechanical cutter, operated from a remote control station with regulated compressed air was designed, built and made operational.

(1) Alfred C. Schwar, Application of Hexanitrostilbene (HNS) in Explosive Components (U), 5C-RR-71 0673, May 1972. 
The proposed cutting procedure specified that both Vee surfaces of the aluminum be incised, normal to the ALSC axis, to about $60 \%$ of sheath thickness. The bending force applied at the incisions should rupture the sheath and break the explosive core with minimal disturbance to the crystalline structure adjacent to the cleft (see Figs. 2 through 5).

Due to the limited availability of HNS II core load, RDX core ALSC $(5.3 \mathrm{~g} / \mathrm{m})$ was used to develop the tooling and technology and produced some rather surprising results:

1. The aluminum sheath was hardened sufficiently to roll the $45^{\circ}$ cutting edge ground on corrosion resistant steel blades (typically number 303 or 304 SS) after three operating contacts. The problem was corrected by replacement with hardened steel alloy blades.

2. The force required to penetrate aluminum sheaths to $60-65 \%$ of thickness was significantly higher for RDX core than HNS II core ALSC ( $1.328 \mathrm{~N}$ versus $1.048 \mathrm{~N}$ respectively). It is doubtful that explosive core density, $91.56 \%$ TMD for RDX and $91.95 \%$ TMD for HNS II, would explain this difference.

3. Best "break" on both RDX and HNS II core loads was achieved by manually applying a bend force at the sheath incision points and against the open Vee to rupture the opposite side, then reversing the force until complete separation occurred.

\section{CONCLUSIONS}

Operational safety in cutting ALSC HNS II would be best achieved by a remotely controlled process for the following reasons:

1. The impact sensitivity data generated in the HNS II drop hammer test series(2) showed one reaction near the $\mathrm{H}_{50}$ height of PETN ( $21 \mathrm{~cm}$ ) indicating that a sharp impact at a discreet point might produce a reaction.

2. Mechanical incisions in the aluminum sheath to $b 0 \%$ or more of sheath thickness are both feasible and controllable thereby eliminating some of the frictions reaction risk normally associated with a full shear cut of sheath and explosive core. It is further recommended that the movable cutter blade be made planar rather than pivotal as in the existing tooling. This recommended design change would contribute substantially to greater precision in scoring the aluminum sheath so that the core break would be more nearly perpendicular to the ALSC axis.

(2) Puntert nata, $2 \mathrm{kig}$ Hrammer and Type $12 \mathrm{~A}$ Toozing. 


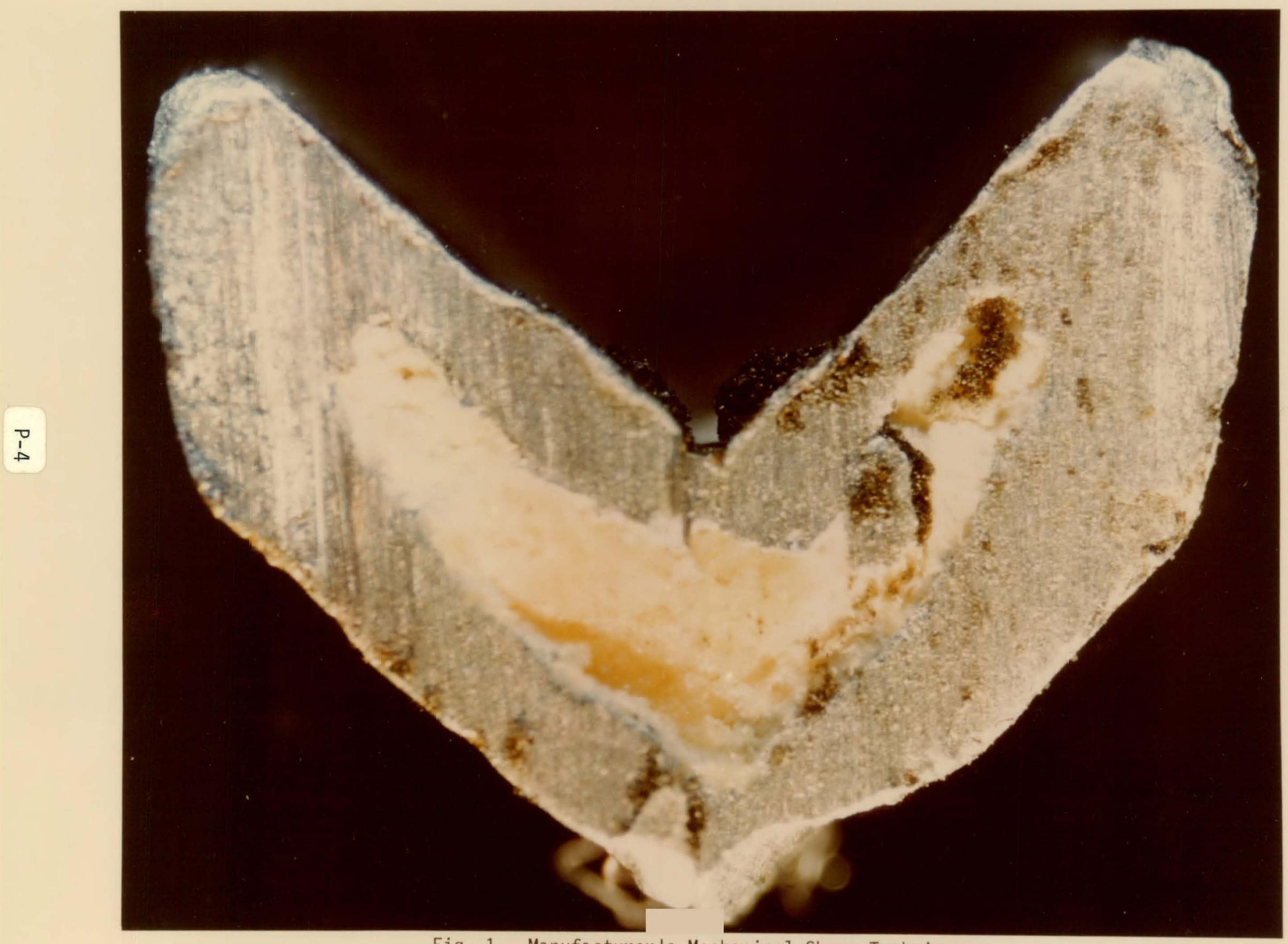

Fig. 1. Manufacturer's Mechanical Shear Technique 


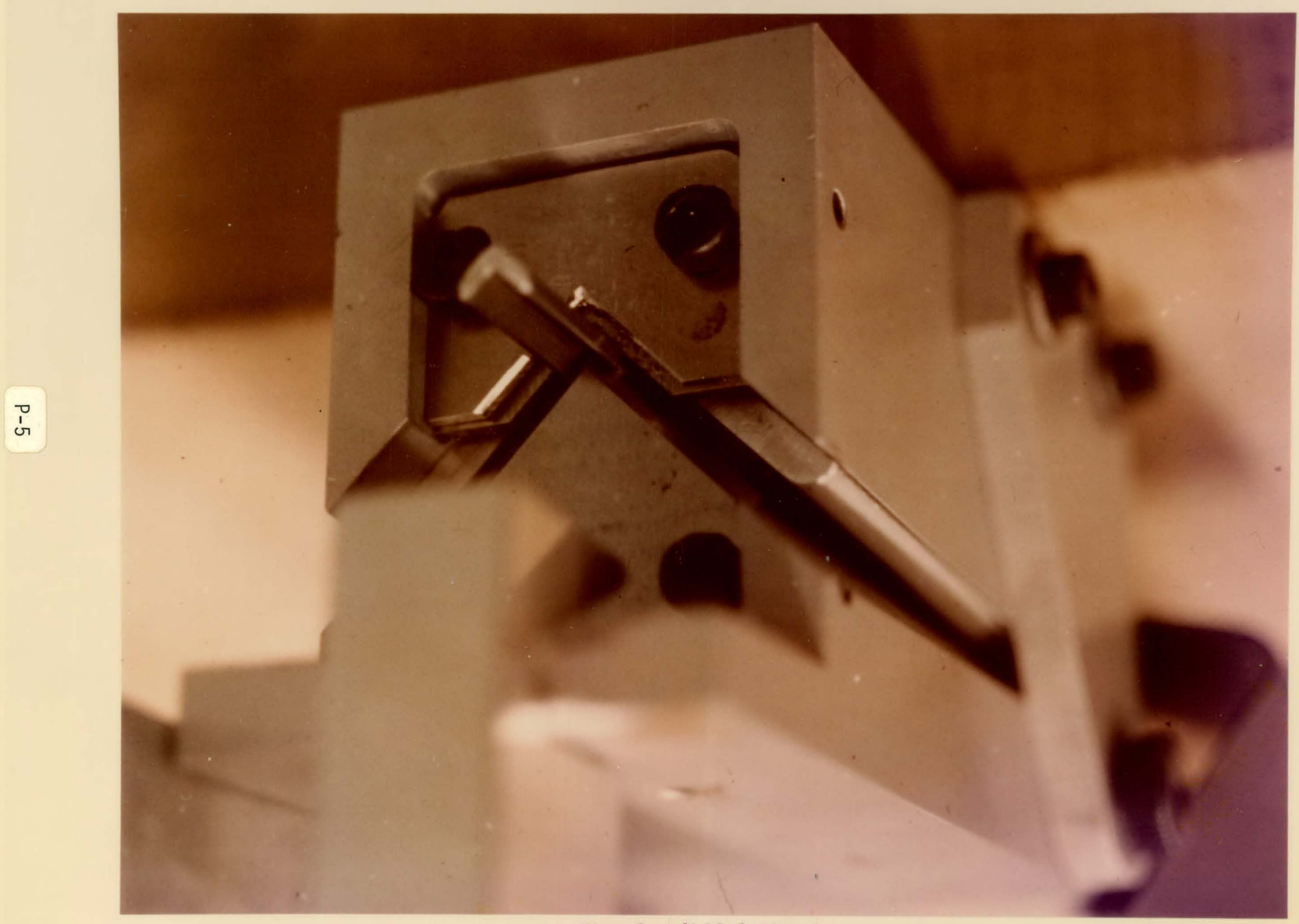

Fig. 2. ALSC Cutter 


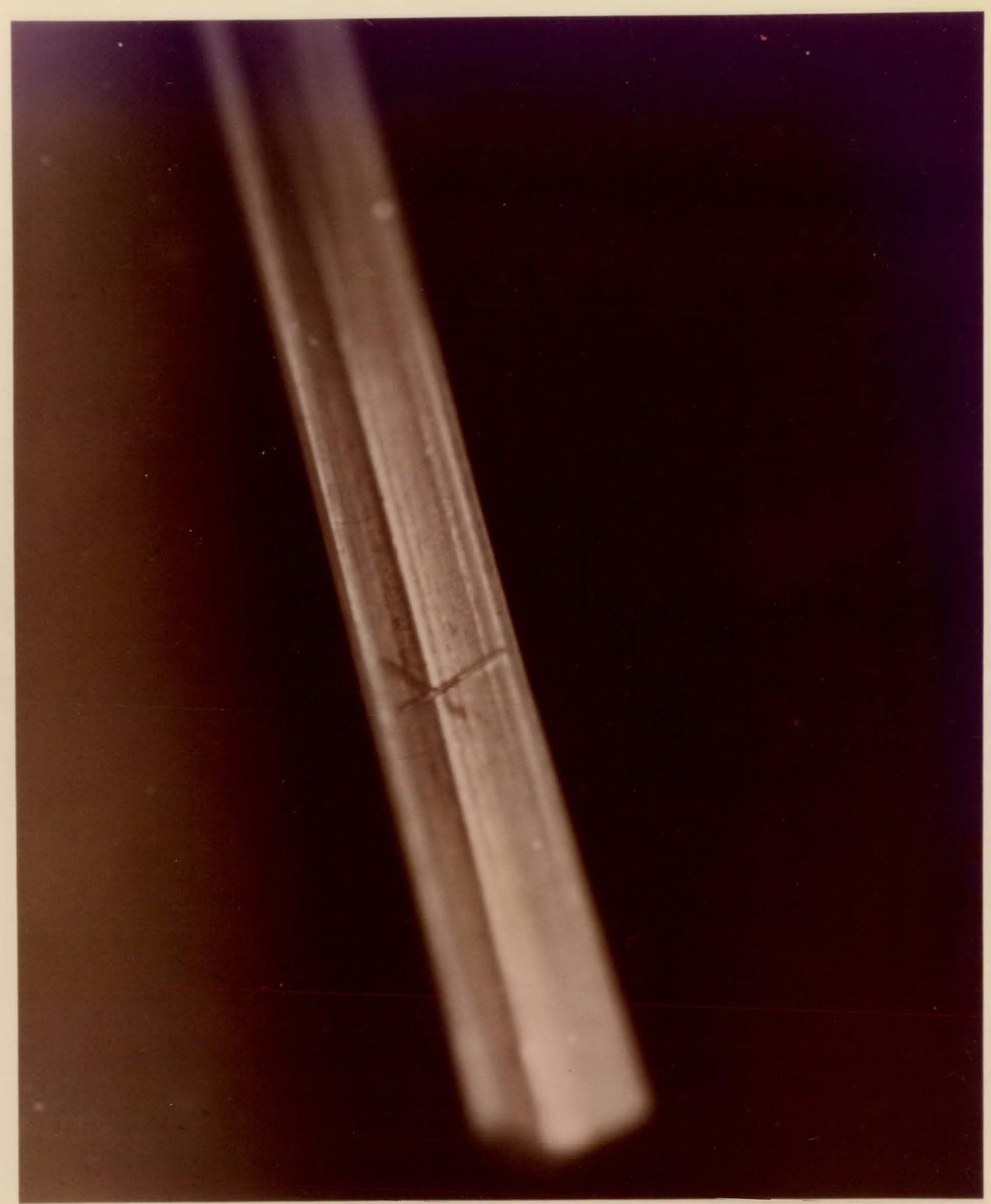

Fig. 3. Incised Sheath 


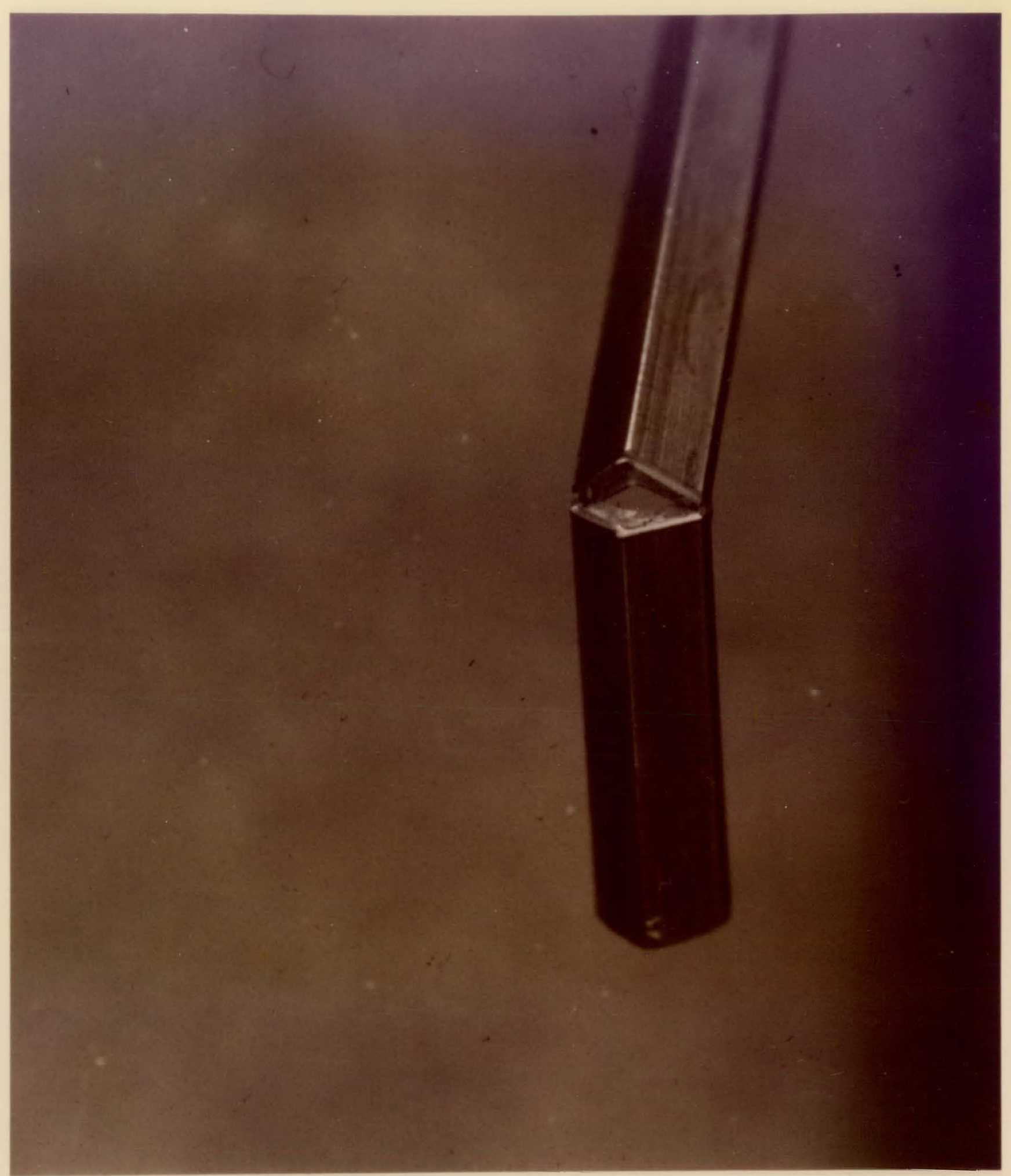

Fig. 4. Incised Sheath Showing Break 


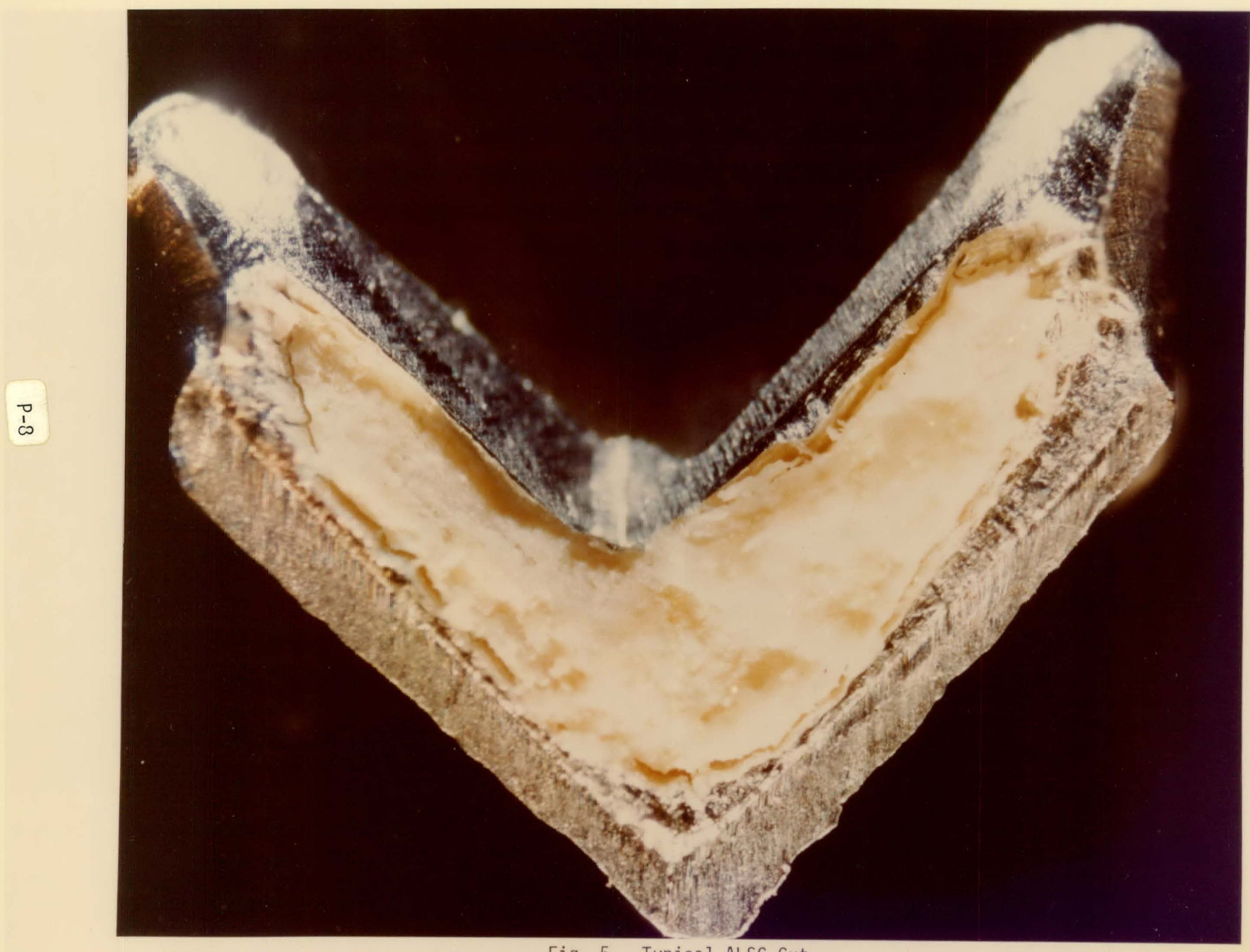

Fig. 5. Typical ALSC Cut 